\title{
The Structural Complexity of Graphene Oxide: the Kirigami Model
}

Aditya Rawala*, Siti H. Che Manº, Vipul Agarwal', Yin $\mathrm{Yao}^{\mathrm{c}}$, Stuart C. Thickett ${ }^{\mathrm{b}+}$, Per B. Zetterlund ${ }^{\mathrm{b}}$

a NMR Facility, Mark Wainwright Analytical Centre, The University of New South Wales, Sydney, NSW 2052, Australia

${ }^{b}$ Cluster for Advanced Macromolecular Design (CAMD), School of Chemical Engineering, The

University of New South Wales, Sydney, NSW 2052, Australia

${ }^{c}$ Electron Microscopy Unit, Mark Wainwright Analytical Centre, The University of New South Wales, Sydney, NSW 2052, Australia

* Corresponding authoremail: a.rawal@unsw.edu.au

${ }^{+}$Present address: School of Physical Sciences (Chemistry), University of Tasmania, Hobart TAS 7001 Australia

\# Present address: Department of Bioprocess and Polymer Engineering, Universiti Teknologi Malaysia, 81310 Skudai, Johor, Malaysia

\section{SUPPORTING INFORMATION}

\section{Table of Contents}

$\begin{array}{ll}\text { Materials Synthesis } & \text { S2 }\end{array}$

$\begin{array}{ll}\text { Dynamic Light Scattering } & \text { S3 }\end{array}$

$\begin{array}{ll}\text { Atomic Force Microscopy } & \text { S3 }\end{array}$

$\begin{array}{ll}\text { Scanning Electron Microscopy } & \text { S4 }\end{array}$

$\begin{array}{ll}\text { X-ray photoelectron spectroscopy } & \text { S4 }\end{array}$

$\begin{array}{ll}\text { Solid State NMR spectroscopy } & \text { S4 }\end{array}$

$\begin{array}{ll}\text { Molecular Mechanics calculation of GO structure } & \text { S6 }\end{array}$

Table S1: A list of the specific structures with suitable abbreviations used in the main textS7

$\begin{array}{ll}\text { Figure S1: Lerf-Klinowski Model } & \text { S8 }\end{array}$

$\begin{array}{ll}\text { Figure S2: Lee-Barnes Model } & \text { S10 }\end{array}$

$\begin{array}{ll}\text { Figure S3: Dekany Model } & \text { S11 }\end{array}$

$\begin{array}{ll}\text { Figure S4: Gao-Ajayan Model } & \text { S13 }\end{array}$

$\begin{array}{ll}\text { Figure S5: Stable Dispersion of GO in water } & \text { S15 }\end{array}$

Figure S6: Solid state ${ }^{13}$ C CPMAS NMR of GO S16

$\begin{array}{ll}\text { Assignment of the carbon species } & \text { S17 }\end{array}$

$\begin{array}{lr}\text { Figure S7: Putative OCO structures in GO } & \text { S20 }\end{array}$

Figure S8: ${ }^{13} \mathrm{C}\left\{{ }^{1} \mathrm{H}\right\}$ Dipolar dephasing spectra of GO $\quad$ S22 
Figure S9: Definition of "edge" carbon functionalities in GO

Figure S10: XPS spectra of GO

Figure S11: Molecular mechanics model of $\sim 2 \mathrm{~nm} \mathrm{GO}$ "patch"

Figure S12: ${ }^{13} \mathrm{C}\left\{{ }^{1} \mathrm{H}\right\}$ Dipolar dephasing based structure of C-O-C and Car. regions

\section{EXPERIMENTAL SECTION}

Material synthesis. Graphite nanofibers (Catalytic Materials LLC, average cross-sectional diameter $\sim 100 \mathrm{~nm}$ ), sulphuric acid (Univar), hydrochloric acid (Univar), potassium persulfate (Sigma Aldrich), phosphorus pentoxide (Ajax), potassium permanganate (Univar) and hydrogen peroxide $30 \% \mathrm{v} / \mathrm{v}$ in water (Ajax) were all used as received. All water used was Milli-Q grade. The GO samples were synthesized by a modified Hummers process ${ }^{1}$. Briefly, concentrated $\mathrm{H}_{2} \mathrm{SO}_{4}(50 \mathrm{~mL})$ was heated to 80 ${ }^{\circ} \mathrm{C}$ in a $500 \mathrm{~mL}$ round bottom flask. $\mathrm{K}_{2} \mathrm{~S}_{2} \mathrm{O}_{8}(1.5 \mathrm{~g})$ and $\mathrm{P}_{2} \mathrm{O}_{5}(1.5 \mathrm{~g})$ were added to the acid and stirred until fully dissolved. Subsequently, graphite nanofibers $(2 \mathrm{~g})$ were added and the mixture was kept at 80 ${ }^{\circ} \mathrm{C}$ for $4.5 \mathrm{~h}$. The mixture was then allowed to cool to room temperature and then diluted with deionized water to terminate the preoxidation reaction. The mixture was filtered and rinsed with additional deionized water $(1 \mathrm{~L})$ to remove residual reactants and finally dried in a vacuum oven at $40{ }^{\circ} \mathrm{C}$. The dried, preoxidized graphite nanofibers were added to a $500 \mathrm{~mL}$ round-bottom flask containing concentrated $\mathrm{H}_{2} \mathrm{SO}_{4}(250 \mathrm{~mL})$, and the mixture was chilled to $0{ }^{\circ} \mathrm{C} . \mathrm{KMnO}_{4}(10 \mathrm{~g})$ was slowly added to the mixture while stirring (the temperature was kept below $10^{\circ} \mathrm{C}$ ). The flask was then placed in a water bath held at $35^{\circ} \mathrm{C}$ and left for $1 \mathrm{~h}$ and $48 \mathrm{~h}$ (the final GO's are labelled GO1 and GO48, corresponding to the oxidation time in this step). Following this, the mixture was transferred into a $2 \mathrm{~L}$ conical flask in an ice bath. Deionized water (1 L) was slowly added to the flask while stirring, taking care so that the temperature did not exceed $55^{\circ} \mathrm{C}$. Subsequently, $50 \mathrm{~mL}$ of $30 \% \mathrm{H}_{2} \mathrm{O}_{2}$ solution was added to the mixture (slowly to avoid violent bubbling). The solution at this stage was bright yellow. Finally, the mixture was 
centrifuged, rinsed with $3.4 \% \mathrm{HCl}$ solution (three times) to remove residual salts, and then rinsed with acetone (three times) to remove residual acid (it was confirmed using $\mathrm{pH}$ paper that the supernatant was neutral). The washing process is crucial because the metal salts and acids must be completely removed from the prepared GO. The final solid GO was dried in air or under vacuum. GO exfoliation was performed via ultrasonication (Branson Model450 200W digital ultrasonifier) of an aqueous dispersion of GO (15 mg mL-1 in water) for different lengths of time on ice, ranging from 2 to 60 minutes. For samples that were ultrasonicated for 60 minutes, the GO dispersion was then centrifuged for 10 minutes at $10000 \mathrm{rpm}$, and the upper supernatant collected (see Figure S5).

Dynamic Light Scattering (DLS). DLS measurements were performed on a Malvern Zetasizer Nanoseries operating a $4 \mathrm{~mW}$ HeNe laser at $633 \mathrm{~nm}$, with backscattering detection at $173^{\circ}$ at room temperature. Five runs were taken for each sample. Note that DLS reported average diameters are based on the assumption of spherical objects, or more specifically the sphere with equivalent diffusion coefficient as determined via autocorrelation data. DLS should only be used as an approximate guide to the dimension of GO nanosheets.

Atomic Force Microscopy (AFM). The graphene oxide was first dispersed in distilled water solution, and to avoid large particles inside the solution, the GO solution was filtered and well sonicated. Then a dilute GO solution was drop casted on a fresh cleaved mica surface (the mica was bonded to a standard AFM stub using silver paste). The AFM measurements were performed on the Bruker Dimension Icon SPM. Peak force tapping mode using the SCANASYST probe (from Bruker AFM probes) was used to perform the measurements. The scan size was firstly set to $10 \mu \mathrm{m}$ in order to find the desired GO sheet, then the scan size was used to $1 \mu \mathrm{m}$ for a higher resolution image. The scan rate as set to around $0.67 \mathrm{~Hz}$ with a peakforce of approximately $400-500 \mathrm{pN}$. The feedback gain was optimized accordingly to optimize tracking of the specimen surface, without any significant feedback noise. The resolution of the 
image was set to 512 pixels per line. AFM images were analysed using Gwyddion 2.55 software and the height profile was averaged between 10 lines of measurements.

Scanning Electron Microscopy (SEM). SEM micrographs were recorded on the Hitachi S-900 SEM at the Mark Wainwright Analytical Centre at UNSW. Samples were uncoated and imaged at a working distance of $\sim 5 \mathrm{~mm}$ (accelerating voltage $4 \mathrm{kV}$ ).

X-ray photoelectron spectroscopy (XPS) was performed on an Escalab250Xi X-ray photoelectron spectrometer (Thermo Scientific) with Al Ka incident radiation $(1486.6 \mathrm{eV})$ at $150 \mathrm{~W}(13 \mathrm{kV}, 12 \mathrm{~mA})$. Survey scans were taken over a binding energy range of $1360-0 \mathrm{eV}(1 \mathrm{eV}$ steps $)$ with a dwell time of $100 \mathrm{~ms}$; higher resolution scans were taken with $0.1 \mathrm{eV}$ steps and a $250 \mathrm{~ms}$ dwell time. Data was analysed using Avantage software (Thermo Scientific).

Solid State Nuclear Magnetic Resonance spectroscopy (NMR). The synthesized GO samples were lyophilized prior to NMR analysis and approximately $25 \mathrm{mg}$ of sample was packed into $4 \mathrm{~mm}$ zirconia rotors with Kel-F caps. GO is highly hygroscopic and ensuring dry samples was the key to obtaining high resolution NMR spectra. The ${ }^{13} \mathrm{C}$ NMR experiments were carried out on Bruker AVANCE III 300 spectrometer with a 7 Tesla superconducting magnet operating at frequencies of $300 \mathrm{MHz}$ and $75 \mathrm{MHz}$ for the ${ }^{1} \mathrm{H}$ and ${ }^{13} \mathrm{C}$ nuclei respectively. The $90^{\circ}$ pulse length for ${ }^{1} \mathrm{H}$ and ${ }^{13} \mathrm{C}$ nuclei was optimized to 3.5 $\mu$ s and $4 \mu \mathrm{s}$, respectively. Qualitative ${ }^{13} \mathrm{C}$ spectra with high signal to noise were acquired at $6.5 \mathrm{kHz}$ magic angle spinning (MAS) using the CP-TOSS scheme, with $1 \mathrm{~ms}$ of cross-polarization contact time. Where required, $40 \mu$ s of gated ${ }^{1} \mathrm{H}$ decoupling was inserted into the TOSS period, which completely suppresses the signals of protonated ${ }^{13} \mathrm{C}$ species and partially suppresses the signals of $\mathrm{CH}_{3}$ species (which have a reduced dipolar coupling due to their fast methyl rotation). Recoupling of the ${ }^{13} \mathrm{C}$ 
Chemical Shift Anisotropy $(\mathrm{CSA})^{2}$ for a period of $47 \mu$ s was used to discriminate between overlapping $s p^{3}$ and $s p^{2}$ hybridized carbon species.

The quantitative ${ }^{13} \mathrm{C}$ Direct Polarization with Magic Angle Spinning ( ${ }^{13} \mathrm{C}$ DPMAS) NMR spectra of the material were acquired at $12 \mathrm{kHz}$ MAS with a ${ }^{13} \mathrm{C} 90^{\circ}$ pulse length of $4 \mu \mathrm{s}, 80 \mathrm{kHz}{ }^{1} \mathrm{H}$ SPINAL64 decoupling, and a Hahn-echo before signal detection to eliminate baseline distortion. $10 \mathrm{~s}$ recycle delays were used for the measurements, where greater than $95 \%$ of the ${ }^{13} \mathrm{C}$ relaxation was observed as determined by ${ }^{13} \mathrm{C}$ cross-polarization $/ \mathrm{T}_{1}\left(\mathrm{CP} / \mathrm{T}_{1}\right)$ filter ${ }^{3}$. Selective suppression of the protonated carbon species was achieved with dipolar dephasing (dephasing time: $68 \mu \mathrm{s}$ ) before acquisition, and yielded a quantitative signal of the protonated and non-protonated carbon species according to the method of Brewer et $\mathrm{al}^{4}$. 4k Transients were acquired for each spectrum to ensure sufficient signal-to-noise ratio and the typical measurement time for each ${ }^{13} \mathrm{C}$ DPMAS experiment was 11 hours.

In previous work ${ }^{5-6}, 2 \mathrm{D}{ }^{13} \mathrm{C}-{ }^{13} \mathrm{C}$ correlation $\mathrm{NMR}$ of isotopically enriched $\mathrm{GO}$ has been applied to address the question of the relative location of the different carbon moieties within the GO structure. While this is the gold standard for establishing carbon-carbon "connectivity", not all the species yielded assignable correlation signals ${ }^{5}$. Furthermore, the present synthesis of natural abundance (i.e. unlabeled) ${ }^{13} \mathrm{C}$ GO precludes this type of experiment. Instead here, the relative location of the carbon moieties within the GO48 structure was elucidated by the 2D ${ }^{13} \mathrm{C}-{ }^{1} \mathrm{H}$ HEteronuclear COrrelation (HETCOR) NMR with 86 kHz of Frequency Switch Lee Goldburg (FSLG) homonuclear decoupling to provide sufficient resolution in the indirect ${ }^{1} \mathrm{H}$ dimension. 64 transients were acquired in steps of $34 \mu \mathrm{s}$ in the indirect dimension (corresponding to an acquisition time of $2 \mathrm{~ms}$ ) to generate the 2D data set. $100 \mu \mathrm{s}$ and $1 \mathrm{~ms}$ of ${ }^{1} \mathrm{H} \rightarrow{ }^{13} \mathrm{C}$ cross polarization contact times to detect the local (1-2 bond) and long range (3-4 bond) ${ }^{1} \mathrm{H}-{ }^{13} \mathrm{C}$ proximities respectively in the $2 \mathrm{D}$ HETCOR spectra. 
Long-range ${ }^{13} \mathrm{C}\left({ }^{1} \mathrm{H}\right)$ dephasing. Long range dephasing refers to the suppression of the NMR signal of quaternary carbon species, where the nearest ${ }^{1} \mathrm{H}$ is 2 or more bonds away. The long range ${ }^{13} \mathrm{C}-{ }^{1} \mathrm{H}$ recoupling experiments ${ }^{7}$ were measured at $13 \mathrm{kHz}$ MAS, with a recycle delay of $10 \mathrm{~s}$. The expected dephasing behavior for 2-bond, 3-bond and $>6$ bond $\mathrm{C}$ to $\mathrm{H}$ distances adapted from Schmidt-Rohr et al. ${ }^{7-8}$ are shown in Figure 4 in the main manuscript, with shorter $\mathrm{C}$ to $\mathrm{H}$ distances resulting in faster dephasing. The expected dephasing behavior is modeled on systems of planar-fused aromatic ring structures, with well-defined geometries and protons along the edges of the ring structure. The dephasing behavior seen for the $\mathrm{GO}$ is expected to show deviation since the local molecular structure is that of a non-planar $s p^{3}$ hybridized sheet, with differences to the expected 2-bond and 3-bond distance.

Molecular Mechanics calculation of GO structure. The ChemDraw 15.1 and Chem3D software was used to draw the different molecular structures in the manuscript and the supporting information. A 3D conformational structure of the GO structure presented in Figure 4 (b) was calculated using the MM2 functionality of Chem3D, which is a basic force field calculation method used to determine the molecular conformation by minimizing the steric energy. 
Table S1. A list of the specific structures with suitable abbreviations used in the main text.

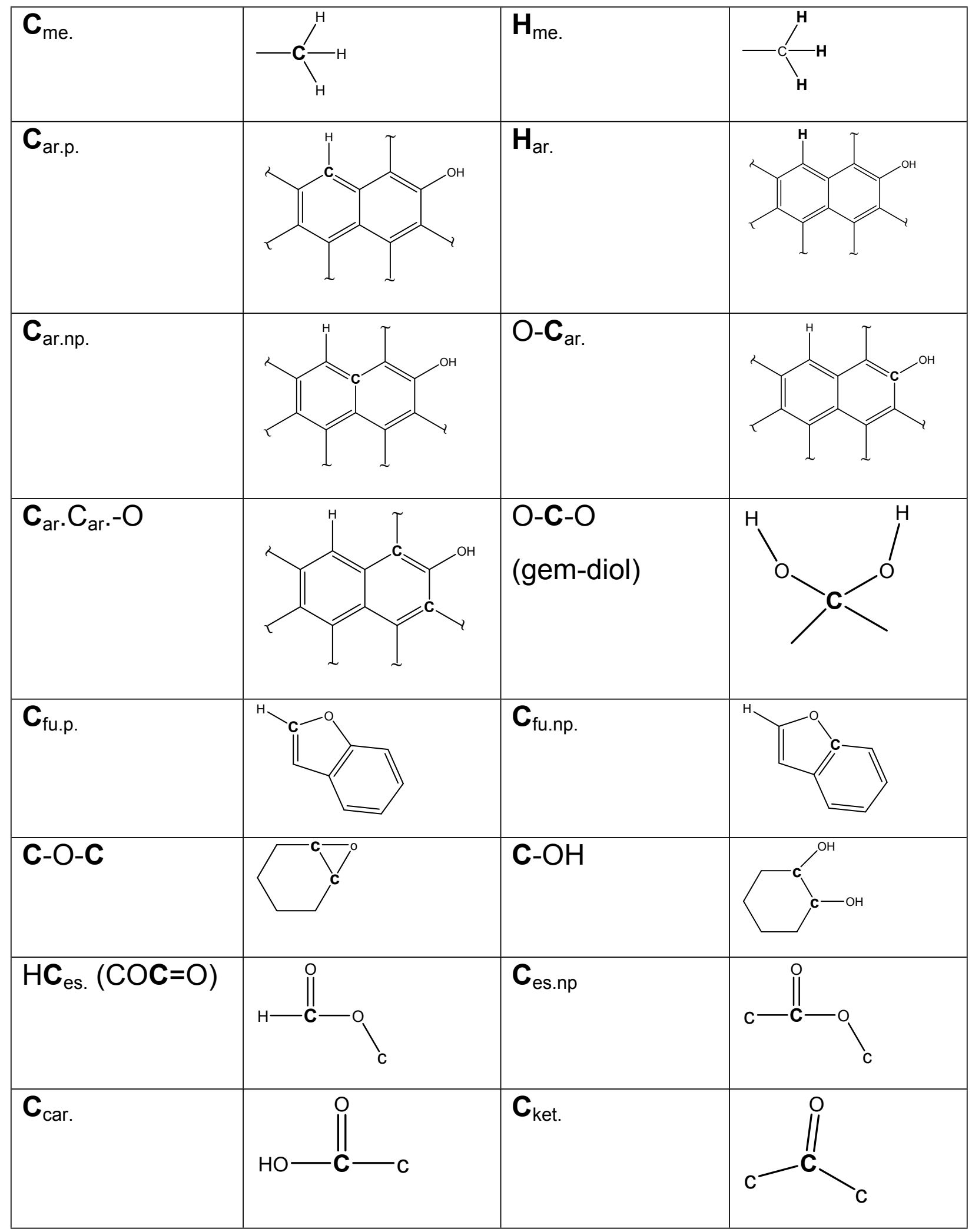




\begin{tabular}{|l|r|l|l|}
\hline Protonated alkene & $\mathrm{C}-\mathbf{C}=\mathbf{C H}-\mathrm{C}$ & & \\
$\mathbf{H}$ & & \\
\hline
\end{tabular}

Comparison of the key GO models in literature. Some of the key proposed GO structures are discussed below. The models, adapted from the relevant papers are assessed in terms of their fit to the ${ }^{13} \mathrm{C}$ NMR spectroscopy presented along with them. In the current adaptation, we assume that the structures presented represent the local GO structure, since the structures have an approximate size of $\sim$ $2-5 \mathrm{~nm}$ and not the structure of a full GO sheet which is $\sim 100$ 's nm. As such, we assume that at least one bond of the edge carbon of the proposed structures (represented by a "broken bond") indicate the continuation of the structure.

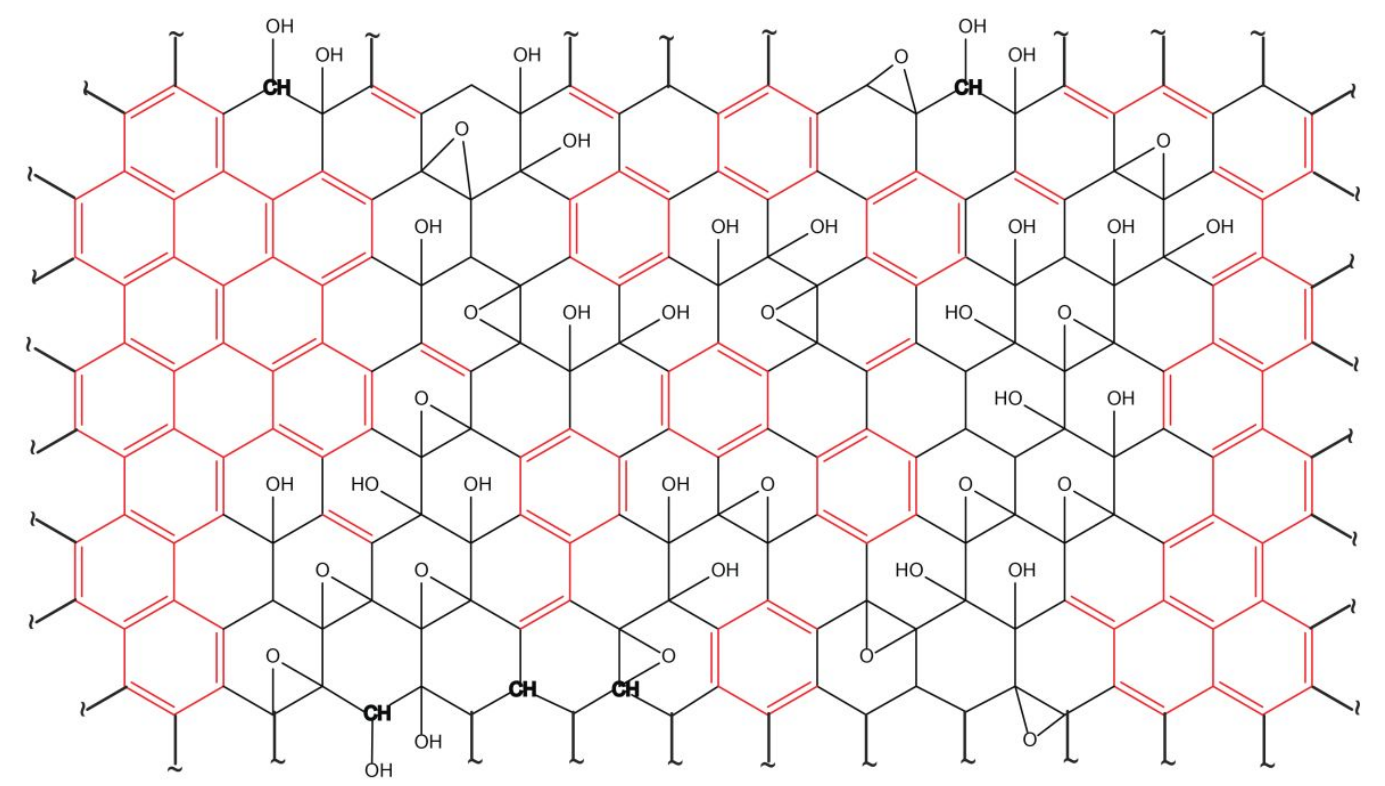

Figure S1. Structural model of GO: The Lerf-Klinowski model adapted from He et al. ${ }^{9}$ The aromatic and diene carbon species are indicated in red. The possible protonated carbon species are indicated in bold. 
Lerf-Klinowski model. The ${ }^{13} \mathrm{C}$ NMR indicates a relatively simple GO structure, with only the $\mathrm{COH}$ COC and $\mathrm{C}_{\mathrm{ar}}$ clearly assignable. From the structure as presented in the paper, it is not clear if the "edge" carbon are identified as $\mathrm{CH}$ and $\mathrm{CH}_{2}$ species. The ${ }^{13} \mathrm{C}$ NMR indicates an approximately 2:1:2 ratio for the $\mathrm{COC}: \mathrm{COH}$ :Car carbon species. The key features of the Lerf-Klinowski model are relatively large fused aromatic ring structures. Although not claimed in the paper, the model presents significant $\mathrm{CH}$ and $\mathrm{CH}_{2}$ species and a few isolated diene structures. The paper states that phenolic species in the structure are formed upon thermal or KI treatment. It is important to note that the phenolic species are indicated to be formed upon reduction within the basal plane, accompanied by a local defect, i.e. breaking of a C-C bond, which is replaced by two phenolic carbon species. As compared to the highly oxidized GO of the present work, the Lerf-Klinowski has significantly fewer functional groups. Within the limit of resolution and quality of the ${ }^{13} \mathrm{C}$ NMR, there appear to be no ketones, OCO, esters, furanic and alkyl species. The system of relatively large fused aromatic ring structures also distinguishes the Lerf-Klinowski model from many other models in the literature. Since there is no information regarding the protonation states and the dipolar dephasing behavior of the carbon species, particularly the aromatic carbon species, it is not possible to draw a reasonable conclusion regarding the details of the structure or extent of the edge carbon species. 


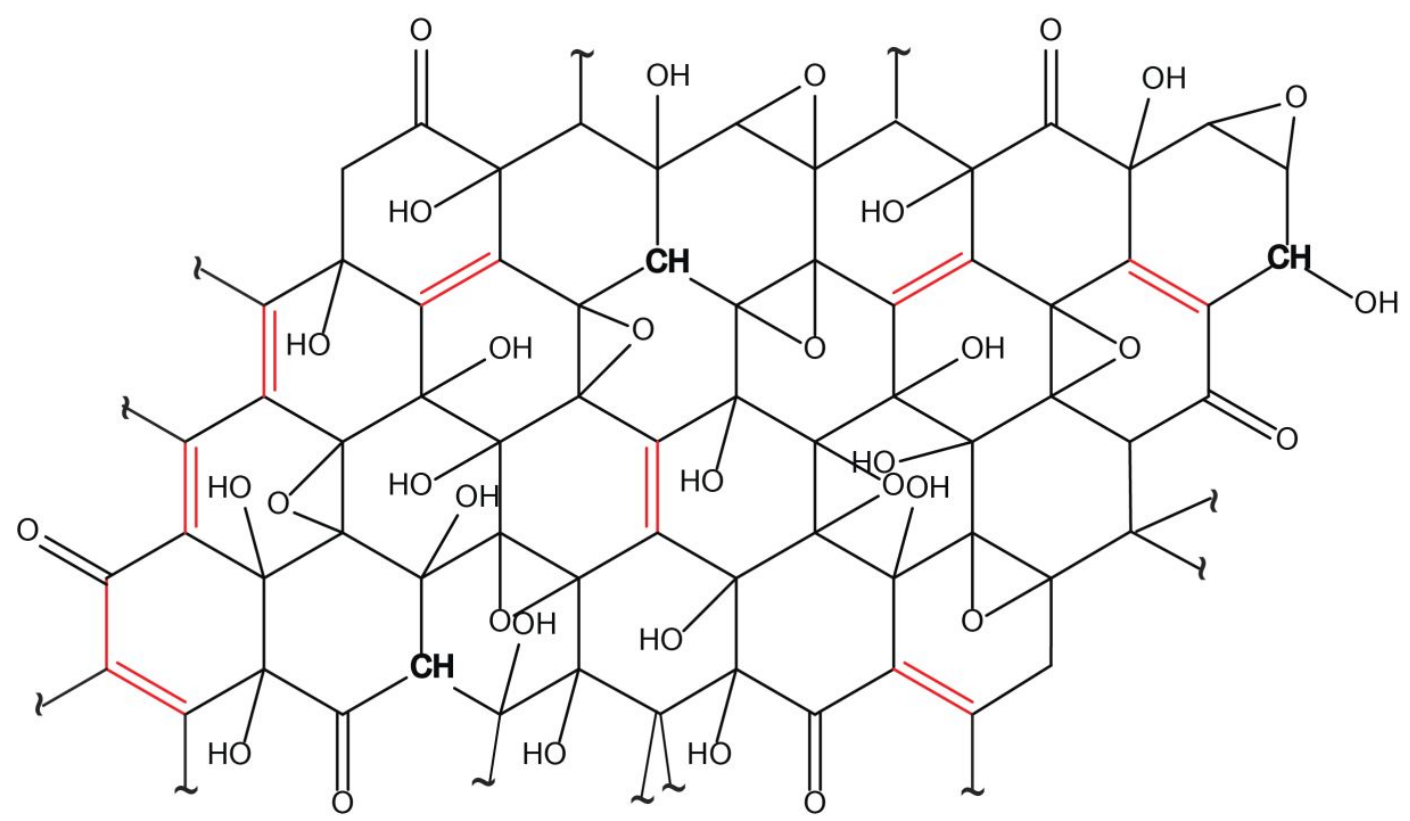

Figure S2. Structural model of GO - The Lee-Barnes model adapted from Lee at al. ${ }^{10} \mathrm{sp}^{2}$ carbons are highlighted in red and the protonated carbon species are identified in bold.

Lee-Barnes model. The key structural details of the Lee-Barnes model are the presence of isolated dienes and a total absence of aromatic rings. Extensive ketones are detected in the ${ }^{13} \mathrm{C}$ NMR and these species are placed in the "edges" of the structure, which considering that this is a local patch of the GO sheet must be associated with "defect" sites in the basal plane. An unusual observation in the paper is the observation of crystalline domains in the selected area electron diffraction pattern of the GO. This should then be consistent with large graphitic domains in the GO which are not indicated in the structure. Alternatively it is possible there was some contamination from graphite in the material. 


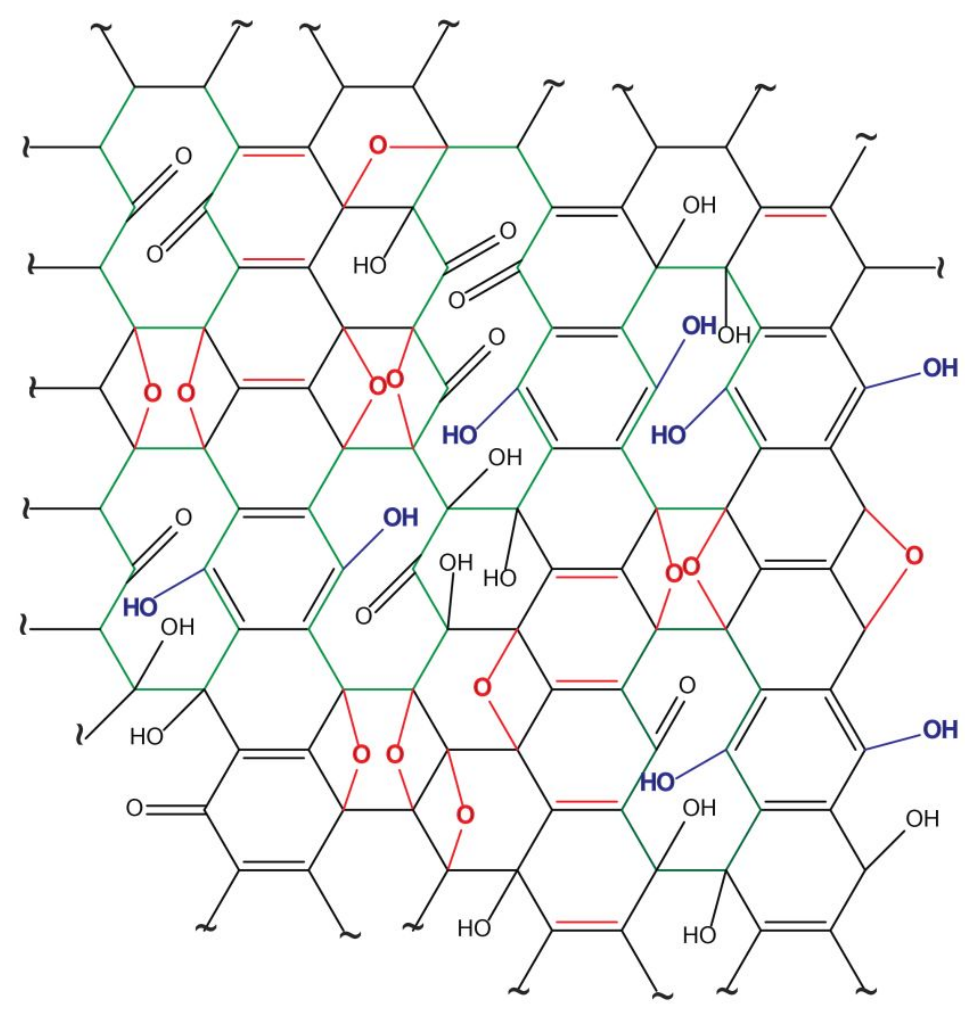

Figure S3. Structural model of GO: The Dekany model adapted from Szabo et al. ${ }^{11} \mathrm{sp}^{2}$ carbons and 1,3 ethers are highlighted in red. Defects/tears in the basal plane associated with $\mathrm{C}=\mathrm{O}$ functionalities are highlighted in green. Extensive phenolic species are highlighted in blue.

Dekany Model. As presented the structure in total shows 108 carbon atoms of which 9 are $\mathrm{C}=\mathrm{O}, 8$ are Phenolic C, 24 are $\mathrm{COC}$ and 12 are $\mathrm{COH}$. In terms of ${ }^{13} \mathrm{C}$ NMR signal intensity, the OCO signal at $100 \mathrm{ppm}$ (not attributed in the paper or addressed in the structure) and $170 \mathrm{ppm}$ are major contributors after the $\mathrm{COC}, \mathrm{COH}$ and $\mathrm{Car}$ species. The structure shows $\mathrm{C}=\mathrm{O}$ and phenolic $\mathrm{C}$ are approximately in equal concentrations, but ${ }^{13} \mathrm{C}$ NMR shows very little phenolic signal, while there is an abundance of $\mathrm{C}=\mathrm{O}$ signal. Note that the phenolics hare are inserted on the basis of the IR spectroscopy. The structure also shows significant isolated dienes which are not expected to be stable to the oxidation conditions of 


\section{Supporting Information}

the GO synthesis. The 1,3 epoxides presented in this structure have been previously discounted by Casabianca et. $\mathrm{al}^{6}$. None of the aromatic or olefinic sites are protonated. However, the structure correctly (in our view) attempts to incorporate the functionalities within the basal plane by accepting breakage of the C-C bond to form local defects as indicated by the green 10 and 14 member rings. An approximate analysis of the ${ }^{13} \mathrm{C}$ NMR spectrum of the most highly oxidized GO in this work indicates a ratio of 2:2:1:1:1 for the $\mathrm{COC}: \mathrm{COH}: \mathrm{OCO}: \mathrm{Car}: \mathrm{C}=\mathrm{O}(\sim 60$ ppm, 70 ppm, 95 ppm, 125 ppm and 170 ppm respectively), as opposed to the ratios of $2: 1: 0: 4: 1: 1$ (ratios of $\mathrm{COC}: \mathrm{COH}: \mathrm{OCO}: \mathrm{Car}: \mathrm{C}=\mathrm{O}$ : $\mathrm{OC}_{\mathrm{ar}}$ ) indicated in the structure. This indicates an edge fraction of $\sim 14 \%$ (by assigning the $\mathrm{C}=\mathrm{O}$ alone to edge species), pointing to a significant defect in the GO basal plane.

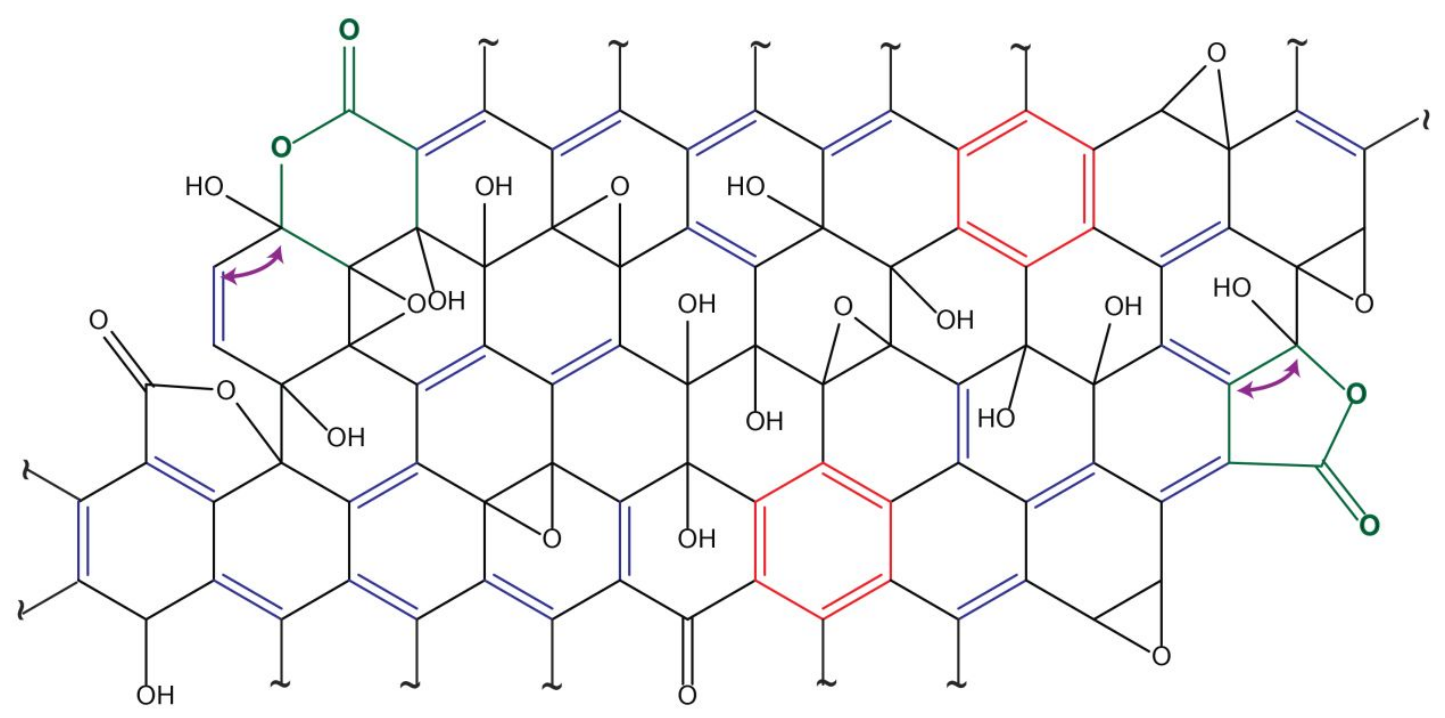

Figure S4. Structural model of GO: The Gao-Ajayan model adapted from Gao et al. ${ }^{12}$ The aromatic rings are highlighted in red, diene $\mathrm{C}$ are highlighted in blue and the proposed lactol rings are highlighted in green. Double headed arrows in purple indicate the ${ }^{13} \mathrm{C}-{ }^{13} \mathrm{C}$ correlation peaks which would be expected if the lactol rings were fused to aromatic sites as indicated in the model. 


\section{Supporting Information}

Gao-Ajayan Model. The Gao-Ajayan model is the most recent model to date. The key features of the structure are few aromatic structures, no fused aromatic rings, mostly isolated or conjugated dienes. The 5 and 6 member ring lactols are the main new features in the structure. As presented, the structure has $56 \mathrm{sp}^{2}$ carbons compared to only $14 \mathrm{COC}$ and $12 \mathrm{COH}$ carbon species, i.e. a factor of 4 more $\mathrm{sp}^{2}$ than $\mathrm{COC} / \mathrm{COH}$. This is an inherent error of the as-presented structure since the high quality direct polarization ${ }^{13} \mathrm{C}$ NMR presented in the manuscript indicates that the ratio of the three primary species must be close to $1: 1: 1$. The structure presents two OCO sites, two ester sites and a single ketone, which is close to the relative intensities of their respective signals in the ${ }^{13} \mathrm{C} \mathrm{NMR}$, and to the relative intensity with respect to the $\mathrm{COC} / \mathrm{COH}$ signals (i.e. $\sim 1 / 6^{\text {th }}$ the intensity). The apart from the issue of the excessive $s p^{2}$ carbon species, the model does not effectively consider the formation of defects, cuts/tears in the GO basal plane which are directly implied by the ${ }^{13} \mathrm{C}$ NMR spectra. Indeed one of the primary arguments for positing the 5 and 6 member lactols is the avoidance for breaking the $\mathrm{C}-\mathrm{C}$ bond and forming a defect. As an important note, the NMR data within the Gao-Ajayan model, and other NMR data including that presented in the current manuscript cannot yield a definitive assignment of the ester carbon as part of the lactol ring. However it is worth pointing out that when the GO is synthesized by the Brodie process, it lacks both the ester and the O-CO ${ }^{13} \mathrm{C}$ NMR signals ${ }^{10}$ (at 165 ppm and 100 ppm respectively).The Gao-Ajayan model description implicitly assumes that the ester, lactol and ketone functionality are located at the external edges of the GO sheet and not within the basal plane. The quantitative ${ }^{13} \mathrm{C}$ NMR presented in the paper shows that collectively, the $\mathrm{C}=\mathrm{O}$, ester and lactol species account for $11 \%$ of the total carbon in the GO, i.e the GO has an edge fraction of $11 \%$ implying

a GO sheet size of $\sim 5 \mathrm{~nm}$. In contrast, the work clearly states that the average GO sheet size is found to be $1 \mu \mathrm{m}$, which corresponds to edge fraction of $<0.1 \%$. Thus the only way to reconcile the NMR spectroscopy and the microscopy is to include extensive cuts/tears into the basal plane of the GO. 


\section{$0.3 \mathrm{~g} \mathrm{GO}$ dispersed in 20} g water $(15 \mathrm{mg} / \mathrm{mL})$

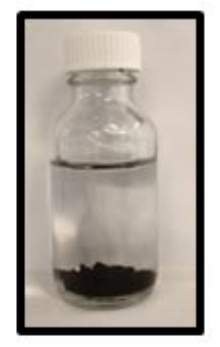

\section{0 min ultrasonication}

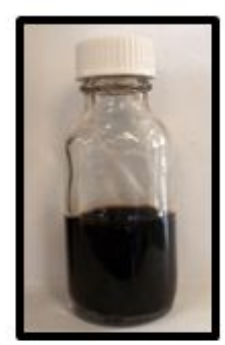

\section{Centrifugation at $10000 \mathrm{rpm}$} For $10 \mathrm{~min}$

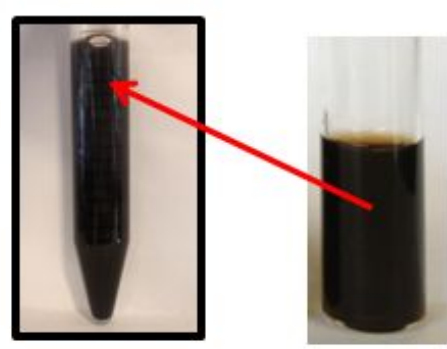

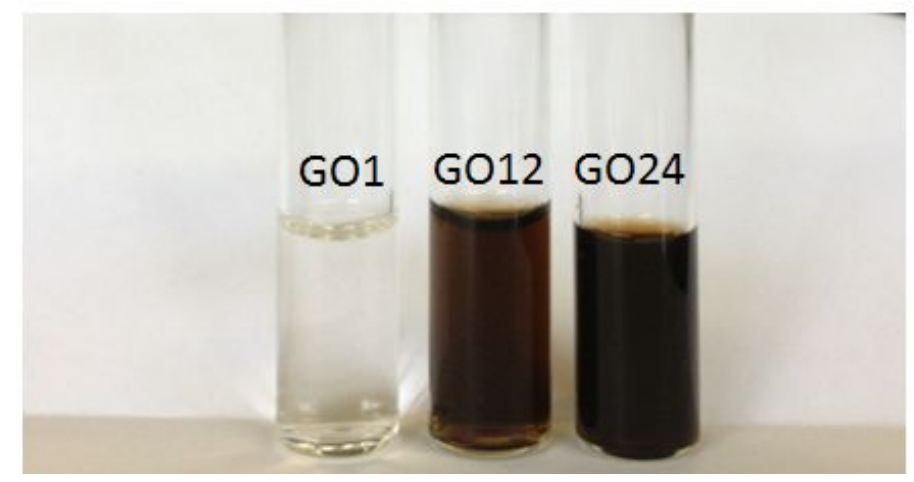

Figure S5. Empirical measurement of the change in chemical structure of GO upon oxidation. After only $1 \mathrm{~h}$ oxidation, GO cannot form a stable dispersion in water. Only after $\geq 12 \mathrm{~h}$ oxidation is a stable GO dispersion possible indicating a significantly increased hydrophilic character. GO48 was not tested to avoid sample loss. 


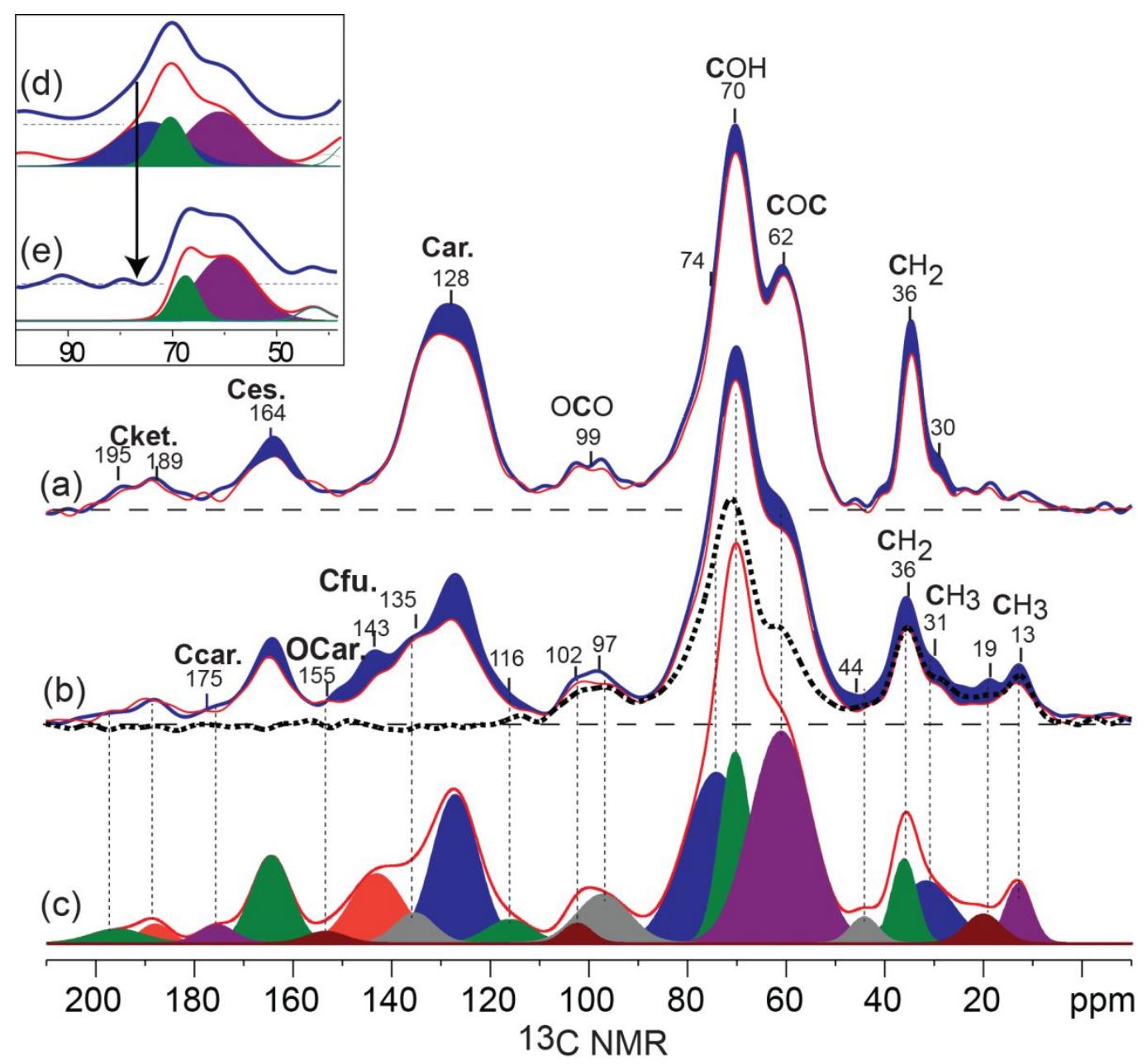

Figure S6. ${ }^{13} \mathrm{C}$ CP-TOSS solid state MAS NMR of GO synthesized with oxidation times of (a) 1 hour and (b) 48 hours. The bold lines and thin lines (blue and red respectively in the online version) are spectra recorded without and with $40 \mu$ s gated of ${ }^{1} \mathrm{H}$ decoupling. The area shaded in light blue is the dephased signal. The dotted line in (b) is ${ }^{13} \mathrm{C}$ spectrum recorded after $47 \mu$ s of CSA recoupling. (c) is a deconvolution identifying the different sites in GO48 based on peak position and peak widths derived from a comparison of the three spectra in (b), with sum of the simulated peaks plotted in green. Inset: (d) is a zoomed in region of the ${ }^{13} \mathrm{C}$ CP-TOSS of GO48 identifying three peaks corresponding two $\mathrm{COH}$ and one COC site. (e) is a scaled difference between the CPTOSS and the CSA recoupled spectrum, where the selective suppression of the $74 \mathrm{ppm}$ site confirms it as a distinct species. 
The quantitative NMR enables us to determine the fraction of protonated $\mathrm{C}_{\mathrm{ar}}$. COC etc. within the GO structure and the values for the relative fractions of the different species are extracted by integrating the area under the curve for each line shape, which are given in Table 1 in the main manuscript. In comparison to GO1, GO48 has a higher concentration of alkyl, alkoxy, protonated-aromatic and furanic carbon species and a reduced concentration of epoxide and condensed aromatic carbon species.

\section{Assignment of the carbon moieties from the 1D NMR.}

Here we systematically identify the distinct secondary moieties, which constitute the structural differences between the structures of GO1, GO48 as well as previously reported GO materials ${ }^{5-6,10,12,15-}$ 16. The presence of methyl and additional alkyl groups in GO48 but not in GO1 is evidenced by the ${ }^{13} \mathrm{C}$ signal at 13, 19 and 24 ppm (Figure $2 \mathrm{a}$ and $\mathrm{b}$ ) which indicate formation of alkyl chains and point to greater degradation of the fused ring GO structure after an extended oxidation time. The partial dephasing of the signal at $36 \mathrm{ppm}$ in both GO1 and GO48 indicates that it is either a quaternary carbon or a protonated alkyl species, with a high degree of local mobility. Additional broad distribution of NMR signals between 24-44 ppm particularly in $\mathrm{GO} 48$ indicate a range of $\mathrm{CH} / \mathrm{CH}_{2}$ moieties.

The O-C-O assignment of the 99 ppm signal (range of 90-105 ppm) O-C-O is not conclusive from previous work ${ }^{12}$, since these chemical shifts ranges are also possible for some $s p^{2}$ or cyclic $s p$ carbon moieties. We conclusive identify the $99 \mathrm{ppm}$ signal as an $s p^{3} \mathrm{O}-\mathrm{C}-\mathrm{O}$ by ${ }^{13} \mathrm{C}$ chemical shift anisotropy (CSA) recoupling ${ }^{2}$ (Figure $2 \mathrm{~b}$, dashed spectrum), which completely suppresses the NMR signals of the $s p^{2}$ and any possible $s p$ carbon moieties but not the 99 ppm peak. Furthermore, the gated dephasing demonstrates that the $\mathrm{O}-\mathrm{C}-\mathrm{O}$ is not protonated and therefore we can also discount the possibility of an acetal (O-CH-O) group. The question then is whether the 99 ppm signal is a cyclic lactol (SI Figure S4) ${ }^{12}$, or its open chain equivalent hemiketal (O-C-O) structure, since both structures have similar chemical shifts, protonation states and chemical shift anisotropies. Insofar as the 1D NMR is concerned, we 


\section{Supporting Information}

cannot distinguish between the two possibilities. Several possible non-ring structures that yield the full range of ${ }^{13} \mathrm{C}$ chemical shifts (in the $105-90 \mathrm{ppm}$ regime) are presented (SI Figure S7) and we hypothesize that within the GO structure, these distinct possibilities do in fact occur. An additional outcome of the CSA filter is a subtle difference in the dephasing behavior of the alkoxy carbons, as shown in the inset (d) and (e) in Figure 2, which identifies a distinct secondary COH site centered at 74 ppm.

The ${ }^{13} \mathrm{C}$ NMR signal at $143 \mathrm{ppm}$ in GO48 yields direct experimental evidence, for the first time, of the formation of furanic carbon $\left(\mathrm{C}_{\mathrm{fu}}\right)$ structures in the $\mathrm{GO}$ structure at extended oxidation times. $\mathrm{C}_{\mathrm{fu}}$. structures have previously been proposed based on computational results in the context of reduced $\mathrm{GO}^{17}$. Nominally the $143 \mathrm{ppm}$ signal could be assigned to quaternary aromatic species. However, partial dephasing of this site (Figure $2 \mathrm{~b}$ ) indicates that at least some of the carbon species associated with the 143 ppm signal are protonated. Within the current knowledge, the only "high ppm" aromatic species that can be protonated are $\mathrm{C}_{\text {fu. }}$, where the carbon adjacent to the oxygen typically has $\mathrm{a} \sim 145 \mathrm{ppm}$ chemical shift ${ }^{18}$. The residual signal from the $143 \mathrm{ppm}$ site after dipolar dephasing can be attributed to the non-protonated $\mathrm{OC}$ carbon in a furan ring, which is potentially bonded to the aromatic (i.e. a benzofuran moiety) or aliphatic sections of the GO. A distinct signal at 155 ppm (Figure $2 \mathrm{~b}$ ) which is not dipolar-dephased identifies a phenolic $\left(\mathrm{O}-\mathrm{C}_{\mathrm{ar}}\right)$ carbon moiety.

The ${ }^{13} \mathrm{C}$ signal at $\sim 165 \mathrm{ppm}$ has generally been assigned to ketonic $\mathrm{C}=\mathrm{O}\left(\mathrm{C}_{\mathrm{ket}}\right)^{11}$, carboxylic $\mathrm{COO}\left(\mathrm{C}_{\mathrm{car}}\right)$ ${ }^{19}$ and ester $\mathrm{OC}=\mathrm{O}\left(\mathrm{C}_{\text {es. }}\right)^{5,12}$ species, although considering the broad nature of the peak, it may well be that multiple distinct species contribute to the signal. In the present case, the partial dephasing of the $165 \mathrm{ppm}$ peak yields the necessary resolution to identify distinct moieties. The dipolar dephased part of the signal is assigned to a protonated terminal $\mathrm{C}_{\text {es. }}$, which is the only moiety to have the right chemical shift and protonation state. The non-dephased signal at $165 \mathrm{ppm}$ is then a quaternary carboxylate ester, 
while a distinct shoulder at $175 \mathrm{ppm}$ identifies the $\mathrm{C}_{\mathrm{car}}$. Significant formation of $\mathrm{C}_{\mathrm{ket}}$. moieties is observed in both GO1 and GO48 as evidenced by the strong ${ }^{13} \mathrm{C}$ signal at $\sim 189 \mathrm{ppm}$, which appear to be ubiquitously present in GO, whether synthesized by the Brodie ${ }^{10}$ or the modified Hummers processes ${ }^{5}$, 12.

Absence of any Nitrogen functionality: The $1 \mathrm{D}{ }^{13} \mathrm{C}$ NMR clearly shows that there are no amines present in the GO, which would be typically expected in the chemical shift range between $\sim 40-60 \mathrm{ppm}$. Additionally the 2D NMR is also definitive about the absence of any N-CH structures in the system, as carbon bonded to nitrogen is expected to exhibit a very strong correlation signal the hydrogen bonded protons $(\mathrm{N} \ldots \mathrm{H})$ at $\sim 9-10 \mathrm{ppm}$ in Figure 3a. In fact the absence of such a correlation signal for the carbon species at $175 \mathrm{ppm}$ also confirms that these are in fact acidic carbon sites $(\mathrm{COOH})$ and not amide type $(\mathrm{NC}=\mathrm{O})$ carbon species. 
I<smiles>O=COC12OC13CCCCC3CC1CCCCC12</smiles>

II

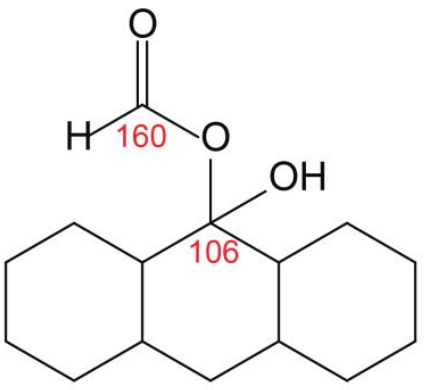

III<smiles>OC1C(O)C(O)(O)C2OC2C2(O)C(O)C3OC3C3C2C1C31CO1</smiles><smiles>O=C1c2ccccc2C(=O)c2ccccc21</smiles>

V

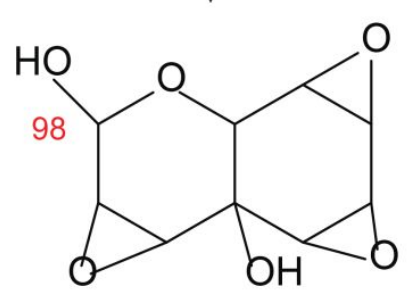

\section{IV}<smiles>O=C1c2ccccc2C(O)(O)c2ccccc21</smiles>

VI

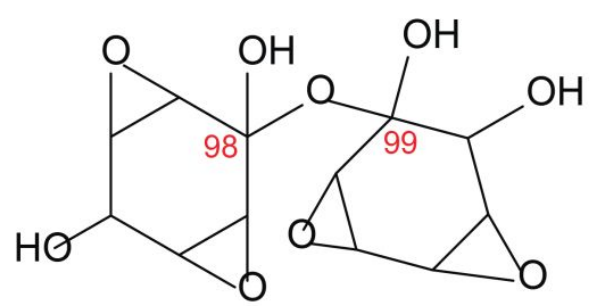

Figure S7. Possible structures for the ${ }^{13} \mathrm{C}$ NMR signal at $99 \mathrm{ppm}$. Chemical shift values predicted using the NMR Predictor in Chemdraw software.

Putative OCO structures. Structures I-VI in Fig.S7 show possible terminal structures other than the ring lactones ${ }^{12}$ that can yield a signal in the $\sim 100$ ppm range ( $\pm 7 \mathrm{ppm}$ range). For I and II the carbon is functionalized with an ester and an epoxide/ OH to form an O-C-O carbon. In III a possible gem-diol can also yield the correct chemical shift. One possible mechanism for the formation of the gem-diol is a keto to gem-diol equilibration process as presented in IV, which is thought to occur in acidic conditions. 
As an example Thangavel et al. ${ }^{13}$ have demonstrated the presence of keto-diol equilibrium for a diazaanthraquinine (DAAQ) in aqueous solution, although crystallization/increased acidity in this case favor the keto form. Generally, the gem-diols are very unstable and revert to the keto form upon dehydration. However exceptions exist, where strong electron withdrawing groups destabilize the partial positive charge on the carbonyl to yield gem-diols in the solid state ${ }^{14}$. While at present for the case of GO, it is an open question as to whether there are electron withdrawing groups formed or protecting groups formed that can stabilize the gem-diol, other structures are also likely such as $\mathrm{V}$ which is a ring lactol (as opposed to a lactone) and structure VI, showing a possible hemiketal structure.

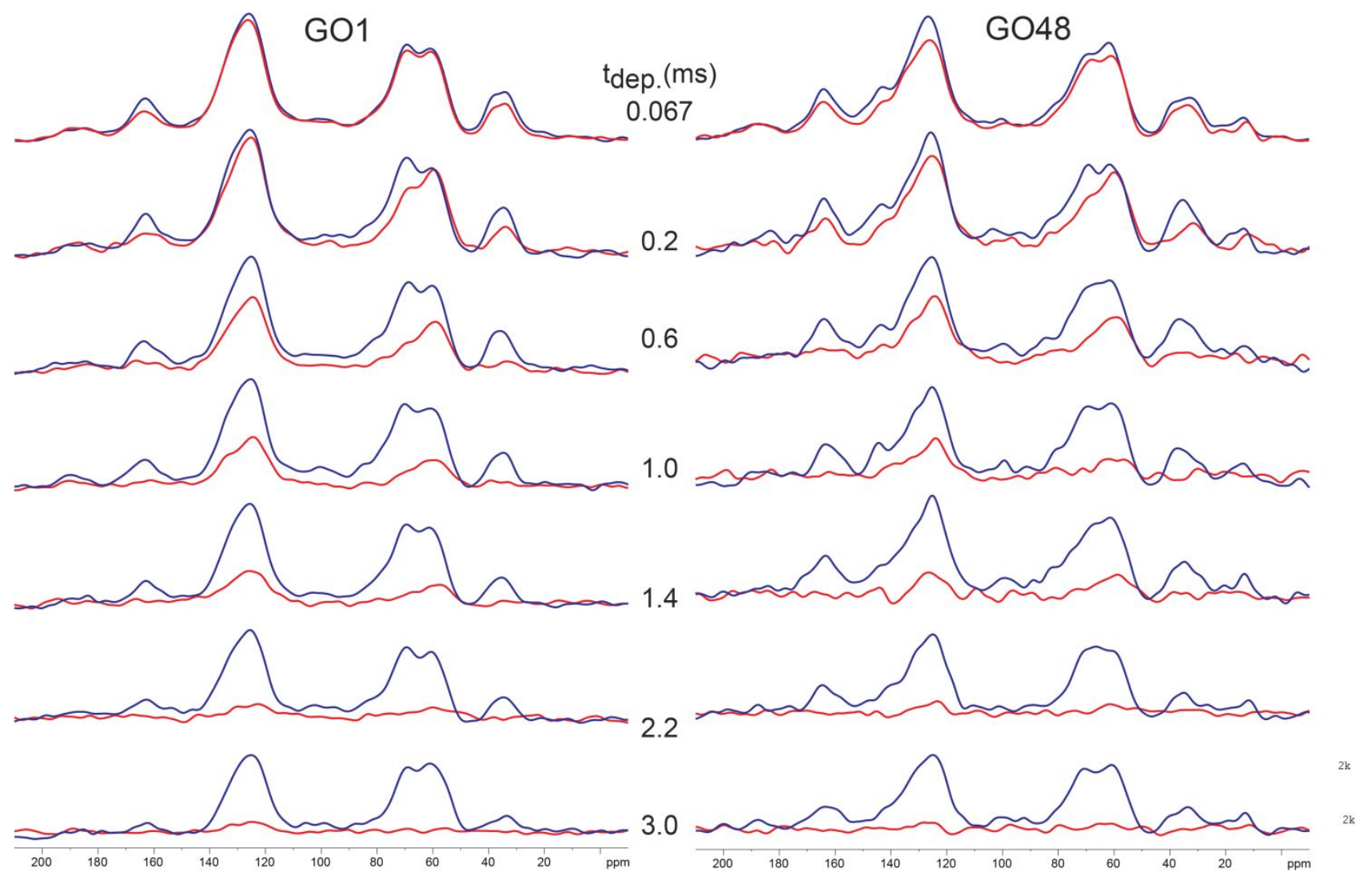

Figure S8. Long-range ${ }^{1} \mathrm{H}$ dipolar dephasing of the ${ }^{13} \mathrm{C}$ NMR signals of GO1 and GO48. Spectra in blue are acquired with the ${ }^{1} \mathrm{H}$ dipolar recoupling pulses turned off, and therefore influenced only by the ${ }^{13} \mathrm{C}$ $\mathrm{T}_{2}$ relaxation. The spectra in red are acquired with ${ }^{1} \mathrm{H}$ dipolar dephasing pulses turned on for recoupling times ranging from $0.067 \mathrm{~ms}$ to $3 \mathrm{~ms}$ as indicated. Scaling of the blue spectrum to the associated red 
spectrum yields the normalized loss in signal intensity for the different carbon species which is plotted in Figure 4.

Note on the long range ${ }^{13} \mathbf{C}\left({ }^{1} \mathbf{H}\right)$ dephasing experiment: In Figure 4 of the main manuscript, we expect that the $\mathrm{COH}$ carbon moieties should all be within a 2-bond distance of the ${ }^{1} \mathrm{H}$, and therefore follow the two bond dephasing curve. However, as mentioned previously, the reference dephasing behavior is measured for a planar fused aromatic ring system, which has shorter $\mathrm{C}$ to $\mathrm{H}$ distances. In the present case of the GO, the nature of the $s p^{3}$ hybridization means longer distances, in addition to the effect of varying $\mathrm{H}$-bonding, which will result in a change of the $\mathrm{C}$ to $\mathrm{H}$ distance. This is consistent with the observed 2D ${ }^{13} \mathrm{C}\left\{{ }^{1} \mathrm{H}\right\}$ HETCOR spectra, where the $\mathrm{OH}$ species have a wide ${ }^{1} \mathrm{H}$ chemical shift distribution, with values of $\sim 10 \mathrm{ppm}$ indicative of the strong hydrogen bonding interactions.

The long range dephasing experiments, enable a more stringent evaluation of the different GO models. For example, the Dekany model ${ }^{11}$ (Figure $\mathrm{S} 4$ ) has $\mathrm{C}_{\mathrm{ar}}$ at a maximum of 2-3 bond distance from ${ }^{1} \mathrm{H}$, which would yield a faster than observed dephasing. On the other hand, the Lerf-Klinowski model ${ }^{9}$ (Figure S2) has large aromatic patches, with 4-5 bond distance to the ${ }^{1} \mathrm{H}$, which would result in significantly slower dephasing of the $\mathrm{C}_{\mathrm{ar}}$ as compared to the COC. The results imply that any aromatic ring that is located in the interior of the $\mathrm{GO}$ sheet will be surrounded by $\mathrm{COH}$ species, rather than $\mathrm{COC}$ or other $\mathrm{C}_{\mathrm{ar}}$.

\section{Definition of edge functionalities}


(a)

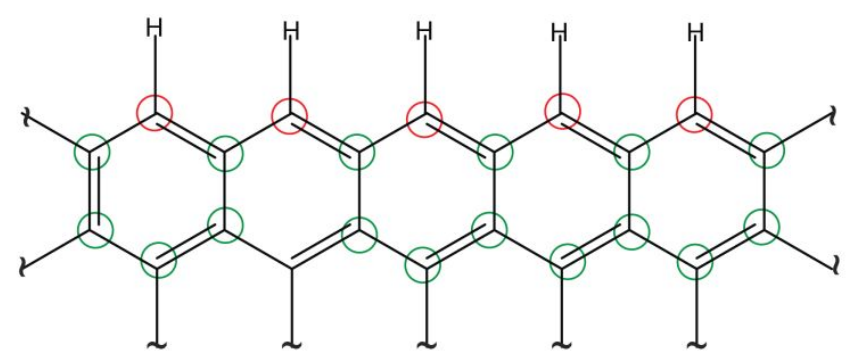

(b)

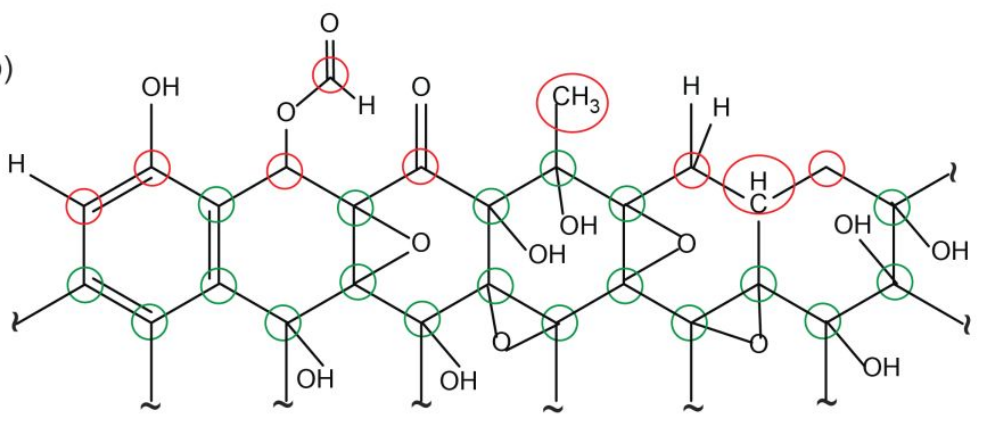

Figure S9. (a) represents the edge functionalities in an ideal graphene sheet. (b) represents the edge functionalities in a functionalized graphene oxide sheet. Red circles identify the spectroscopically resolvable edge carbon moieties while the green circles represent the carbon moieties that are part of the interior. Note that in the zig-zag edge, only those carbon moieties that are bonded to one or two other carbons are identifiable as the "edge", while a carbon bonded to three other carbon is considered to be "interior". This definition is taken into account while calculating the edge vs size ratio in Figure 5 of the main manuscript.

Description of Figure 5 in the manuscript. Figure 5 (a) shows how the \% of edge carbon and the size of graphene sheet in $\mathrm{nm}$ (right axis) vary as the function of the numbers of rings (hexagons) along a single dimension. For example a sheet sized of $100 \times 100$ fused rings has a linear cluster size of 100 rings. Blue circles show how the edge fraction decreases as the linear size increases. Red triangles show how the graphene sheet size in $\mathrm{nm}$ increases. For an estimated $20 \%$ edge carbon, we need a sheet size of $\sim 9 \mathrm{x} 9$ rings, which correspond to $\sim 200$ carbon atoms and $2 \mathrm{~nm}$ in lateral dimension. An alternative to a finite 


\section{Supporting Information}

square sheet, is to consider an infinite chain of fused rings with increasing width, i.e. 1 ring wide, 2 ring wide etc. Here for example a 1 ring wide infinite chain has $50 \%$ edge carbon. For $20 \%$ edge, we estimate 4-5 ring wide infinite $(\sim 1$ micron) chains. However the chemical structure measurements from the NMR spectroscopy, where, counting the protonated Car. $\mathrm{HCOO}-, \mathrm{CH}_{3}, \mathrm{HC}_{\text {fur }}$, and the ester carbons as edge species, we have the edge carbons comprising $\sim 20 \%$ of the overall carbon in the GO. This is an unusually

high value, and would indicate much smaller sizes for the GO sheets than those indicated by the DLS. For example, assuming a simplified fused ring structure, at most a cluster of 9 x 9 rings, fused in a hexagonal motif, with an expected size of only $2 \mathrm{~nm} \times 2 \mathrm{~nm}$ would yield the required $20 \%$ of edge carbons. This is clearly much smaller that the sizes observed by microscopy. An alternative motif comprising of fused ring chains, finite in width, but having a long (in fact any arbitrary) length, would also yield the required $20 \%$ edge carbons for a 4-5 ring wide chain ( $1 \mathrm{~nm}$ width). This could reconcile the DLS measurements, where for example, a high molecular weight polymer chain can have a very large radius of gyration. However in such a case we would observe distinct ribbon like morphology in the various SEM, TEM and AFM measurements of the GO, which again is not consistent with the literature ${ }^{11,20-22}$, where the GO's synthesized by a variety of processes consistently show a plate like morphology with dimensions of 100's of $\mathrm{nm}$. 

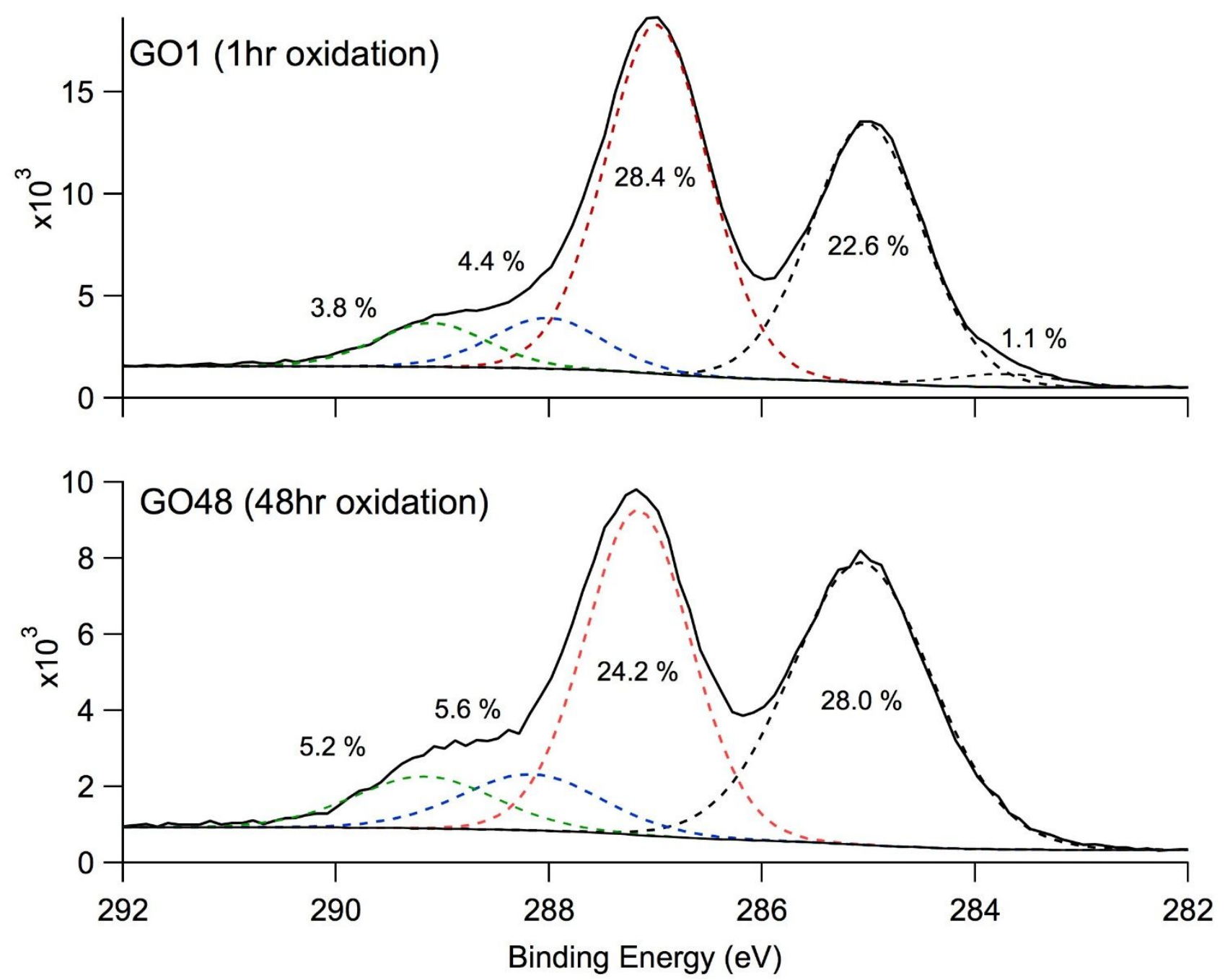

Figure S10. High-resolution C1s XPS spectra of GO1 (top panel) and GO48 (bottom panel). The C:O atomic ratios for GO1 and GO48 were 1.65 and 1.87 respectively, as determined by XPS survey scans, which within the error of measurement represent similar C:O ratios. The percentages shown represent the atomic abundance of various populations of different carbon bonding environments as determined by $\mathrm{C} 1 \mathrm{~s}$ peak deconvolution. Key: dashed black line $=s p^{3} \mathrm{C}=(285.0 \mathrm{eV})$; dashed red line $=\mathrm{C}-\mathrm{O}(287.0$ $\mathrm{eV})$; dashed blue line $\mathrm{C}=\mathrm{O}(288.1 \mathrm{eV})$; dashed green line $=\mathrm{O}-\mathrm{C}=\mathrm{O}(289.1 \mathrm{eV})$. Also present in the $\mathrm{GO} 1$ spectrum is a peak at $238.8 \mathrm{eV}\left(\right.$ likely $\left.s p^{2} \mathrm{C}\right)$. 


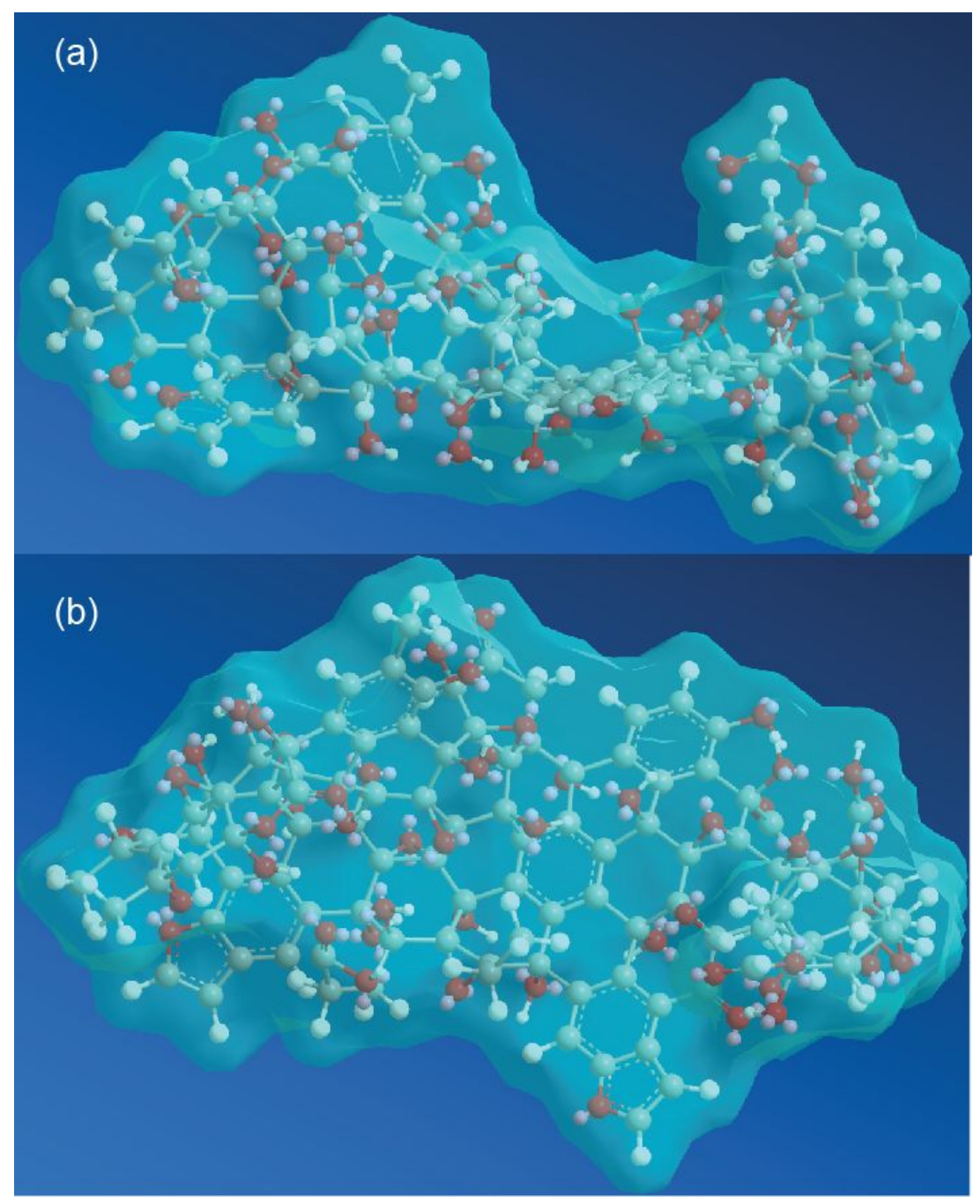

Figure S11. A molecular mechanics based 3D model of the GO48 patch presented in Figure 4 (b) of the main manuscript. (a) is a side view and (b) is a top view, while the transparent surface represents the solvent accessible surface of the GO patch. The aromatic domain in the middle of the GO patch forms a flat surface surrounded by a curved region of the aliphatic and oxidized carbon moieties. Solvent interactions are not considered in the present rendering. 

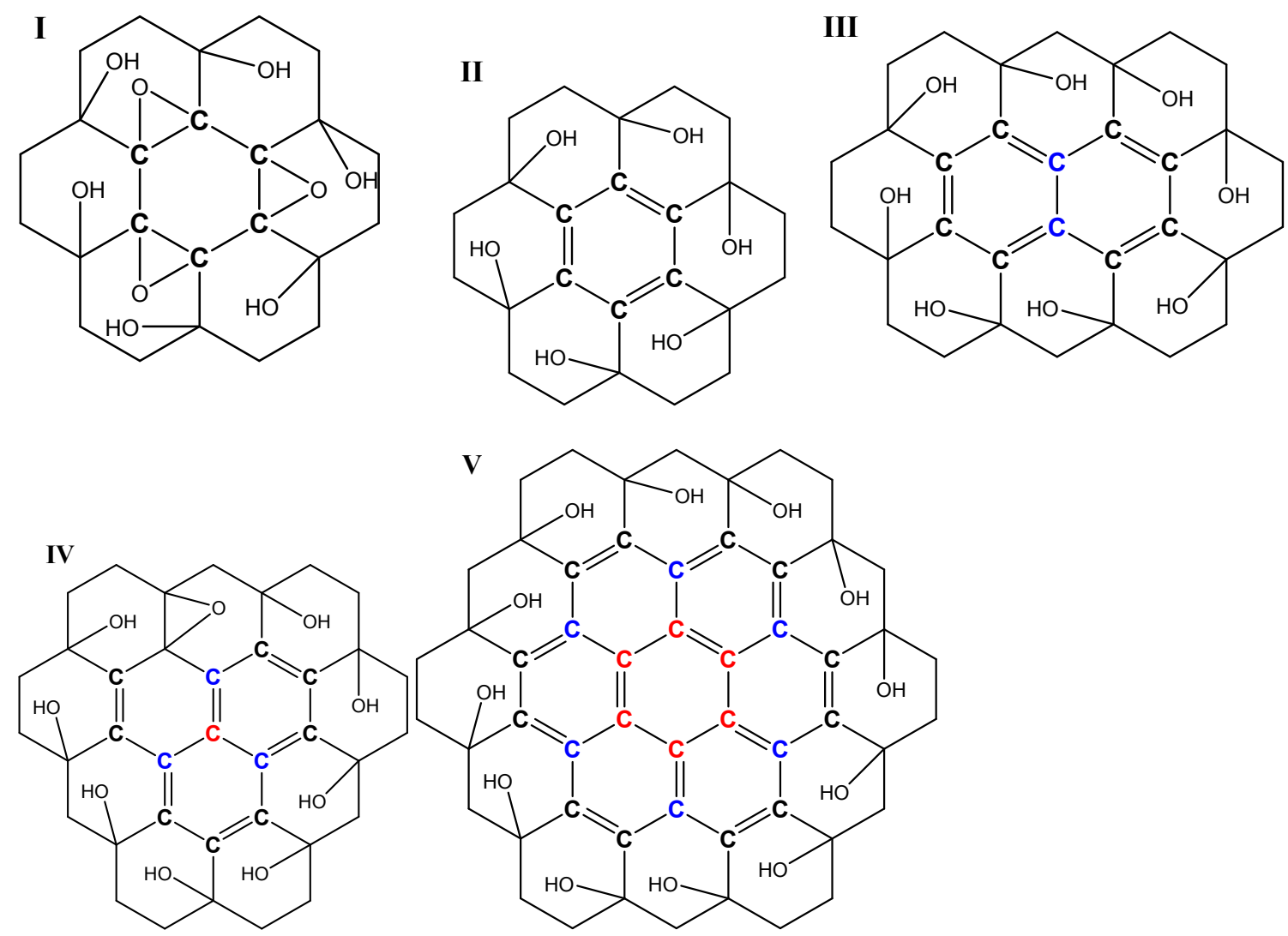

Figure S12. Examples of possible local environments of the Car. and COC carbon species, as deduced from the dephasing behavior in Figure 4a of the main manuscript. The dominant dephasing behavior of these two carbon species is very similar, implying that these carbon sites similar proximity $\sim 3-4$ bond proximity to nearby proton sites. This condition is best satisfied in the case of structures I and II and III, where the $\mathrm{COC}$ and Car sites are always surrounded by $\mathrm{COH}$ sites at a 3 bond distance. On the other hand if we consider larger clusters, especially of fused aromatic rings such as presented in structures IV and V, then a significant number of carbon sites begin to occur at 5-4 bond lengths from the $\mathrm{H}$, which would result is a much slower dephasing curve.

\section{References}

1. Luo, J.; Cote, L. J.; Tung, V. C.; Tan, A. T. L.; Goins, P. E.; Wu, J.; Huang, J., Graphene Oxide Nanocolloids. J. Am. Chem. Soc. 2010, 132 (50), 17667-17669. 
2. Mao, J. D.; Schmidt-Rohr, K., Separation of aromatic-carbon 13C NMR signals from dioxygenated alkyl bands by a chemical-shift-anisotropy filter. Solid State Nucl. Magn. Reson. 2004, 26 (1), 36-45.

3. Torchia, D. A., Measurement of proton-enhanced C-13 T1 values by a method which suppresses artifacts J. Magn. Reson. 1978, 30 (3), 613-616.

4. $\quad$ Brewer, C. E.; Schmidt-Rohr, K.; Satrio, J. A.; Brown, R. C., Characterization of biochar from fast pyrolysis and gasification systems. Environ. Prog. Sustain. 2009, 28 (3), 386-396.

5. $\quad$ Cai, W.; Piner, R. D.; Stadermann, F. J.; Park, S.; Shaibat, M. A.; Ishii, Y.; Yang, D.; Velamakanni, A.; An, S. J.; Stoller, M.; An, J.; Chen, D.; Ruoff, R. S., Synthesis and solid-state NMR structural characterization of (13)C-labeled graphite oxide. Science 2008, 321 (5897), 1815-1817.

6. Casabianca, L. B.; Shaibat, M. A.; Cai, W. W.; Park, S.; Piner, R.; Ruoff, R. S.; Ishii, Y., NMRBased Structural Modeling of Graphite Oxide Using Multidimensional C-13 Solid-State NMR and ab Initio Chemical Shift Calculations. J. Am. Chem. Soc. 2010, 132 (16), 5672-5676.

7. Mao, J. D.; Schmidt-Rohr, K., Recoupled long-range C-H dipolar dephasing in solid-state NMR, and its use for spectral selection of fused aromatic rings. J. Magn. Reson. 2003, 162 (1), $217-227$. 8. $\quad$ Fang, X.; Mao, J.; Levin, E. M.; Schmidt-Rohr, K., Nonaromatic Core-Shell Structure of Nanodiamond from Solid-State NMR Spectroscopy. J. Am. Chem. Soc. 2009, 131 (4), 1426-1435.

9. He, H. Y.; Klinowski, J.; Forster, M.; Lerf, A., A new structural model for graphite oxide. Chem. Phys. Lett. 1998, 287 (1-2), 53-56.

10. Lee, D. W.; De Los Santos V, L.; Seo, J. W.; Felix, L. L.; Bustamante D, A.; Cole, J. M.; Barnes, C. H. W., The Structure of Graphite Oxide: Investigation of Its Surface Chemical Groups. $J$. Phys. Chem. B 2010, 114 (17), 5723-5728.

11. Szabo, T.; Berkesi, O.; Forgo, P.; Josepovits, K.; Sanakis, Y.; Petridis, D.; Dekany, I., Evolution of surface functional groups in a series of progressively oxidized graphite oxides. Chem. Mater. 2006, 18 (11), 2740-2749.

12. Gao, W.; Alemany, L. B.; Ci, L.; Ajayan, P. M., New insights into the structure and reduction of graphite oxide. Nat. Chem. 2009, 1 (5), 403-408.

13. Thangavel, A.; Elder, I. A.; Sotiriou-Leventis, C.; Dawes, R.; Leventis, N., Breaking Aggregation and Driving the Keto-to-gem-Diol Equilibrium of the N,N' -Dimethyl-2,6-diaza-9,10anthraquinonediium Dication to the Keto Form by Intercalation in Cucurbit[7]uril. The Journal of Organic Chemistry 2013, 78 (17), 8297-8304.

14. Crespi, A. F.; Vega, D.; Chattah, A. K.; Monti, G. A.; Buldain, G. Y.; Lázaro-Martínez, J. M., gem-Diol and Hemiacetal Forms in Formylpyridine and Vitamin-B6-Related Compounds: Solid-State NMR and Single-Crystal X-ray Diffraction Studies. The Journal of Physical Chemistry A 2016, 120 (39), 7778-7785.

15. Park, S.; Hu, Y.; Hwang, J. O.; Lee, E.-S.; Casabianca, L. B.; Cai, W.; Potts, J. R.; Ha, H.-W.; Chen, S.; Oh, J.; Kim, S. O.; Kim, Y.-H.; Ishii, Y.; Ruoff, R. S., Chemical structures of hydrazinetreated graphene oxide and generation of aromatic nitrogen doping. Nat. Commun. 2012, 3, 638. 16. MacIntosh, A. R.; Harris, K. J.; Goward, G. R., Structure and Dynamics in Functionalized Graphene Oxides through Solid-State NMR. Chem. Mater. 2016, 28 (1), 360-367.

17. Bagri, A.; Mattevi, C.; Acik, M.; Chabal, Y. J.; Chhowalla, M.; Shenoy, V. B., Structural evolution during the reduction of chemically derived graphene oxide. Nat. Chem. 2010, 2 (7), 581-587. 18. Anderson, J. M.; Johnson, R. L.; Schmidt-Rohr, K.; Shanks, B. H., Solid state NMR study of chemical structure and hydrothermal deactivation of moderate-temperature carbon materials with acidic SO3H sites. Carbon 2014, 74, 333-345. 
19. Lerf, A.; He, H.; Forster, M.; Klinowski, J., Structure of Graphite Oxide Revisited. J. Phys. Chem. B 1998, 102 (23), 4477-4482.

20. Marcano, D. C.; Kosynkin, D. V.; Berlin, J. M.; Sinitskii, A.; Sun, Z.; Slesarev, A.; Alemany, L. B.; Lu, W.; Tour, J. M., Improved Synthesis of Graphene Oxide. Acs Nano 2010, 4 (8), 4806-4814.

21. Chen, S.; Zhu, J. W.; Wu, X. D.; Han, Q. F.; Wang, X., Graphene Oxide-MnO2 Nanocomposites for Supercapacitors. Acs Nano 2010, 4 (5), 2822-2830.

22. Voiry, D.; Yang, J.; Kupferberg, J.; Fullon, R.; Lee, C.; Jeong, H. Y.; Shin, H. S.; Chhowalla, M., High-quality graphene via microwave reduction of solution-exfoliated graphene oxide. Science 2016. 